\title{
El Riesgo de Victimización a Menores en el Ámbito Judicial por Privaciones de Patria Potestad u Ordenes de Alejamiento de Larga Duración sin Contactos Supervisados
}

\section{The Risk of Victimization on Children in the Judicial Sphere due to the Withdrawal of Parental Autorithy or Long-Term Restraining Orders Without Overseen Contacts}

\author{
Rafael Delgado Campos \\ Ayuntamiento de Madrid, España
}

\begin{abstract}
Resumen. Trabajo de reflexión sobre los efectos perturbadores en los menores de edad a nivel emocional, relacional y conductual debido a la separación abrupta y duradera de sus figuras vinculares como consecuencia de la privación de la patria potestad u órdenes de alejamiento adoptadas en un contexto judicial en casos de maltrato físico a menores sin contactos supervisados por profesionales. Propuestas de reflexión tendentes a aminorar los riesgos de la producción en dichos menores de una victimización no buscada teniendo en cuenta la conciliación entre la efectiva realización de la justicia y las necesidades vinculares, emocionales y psicológicas de los menores de edad.

Palabras clave: victimización, privación de patria potestad, ruptura vincular, deprivación, contactos supervisados.
\end{abstract}

\begin{abstract}
Reflection work on the disruptive effects on children emotional, relational and behavioral balance due to their abrupt and lasting separation of relational figures as a result of the withdrawal of parental authority or restraining orders taken in a judicial context in cases of abuse children without contacts monitored by professionals. Proposals for thought to reduce the risk of production in those minors of an unintended victimization taking into account the balance between the effective realization of justice and relational, emotional and psychological needs of children.

Keywords: victimization, withdrawal of parental authority, break link, deprivation, overseen contacts.
\end{abstract}

"Desde luego, se puede desarrollar apego a pesar de repetidos castigos impartidos por la figura elegida."

$$
\text { John Bolwy (1979/2006) }
$$

El presente texto encuentra su origen en la observación de los efectos emocionales y conductuales en

El autor es Psicólogo del Centro de Atención a la Infancia del Ayuntamiento de Madrid, Psicólogo de la Asociación Centro de Apoyo al Menor y Abogado, práctica privada.

La correspondencia sobre este artículo debe enviarse al autor al email: rafadelgados@yahoo.es menores de diferentes edades como consecuencia de la separación de sus figuras de apego debido a la adopción de órdenes de alejamiento o sentencias privativas de la patria potestad durante un prolongado periodo de tiempo, sin que se contemple un régimen de visitas o contactos supervisado.

El contexto en el que tiene lugar dicha observación es en los Centros de Atención a la Infancia del Ayuntamiento de Madrid. La función de dichos recursos es intervenir en aquellas situaciones de desprotec- 
ción de los menores, constitutivas bien de riesgo bien de desamparo, en las que las funciones parentales de crianza y protección están desvirtuadas o alteradas, perjudicando el adecuado desarrollo evolutivo de los mismos y su crecimiento como sujetos autónomos. Las situaciones objeto de intervención en los Centros de Atención a la Infancia son aquéllas en las que las necesidades básicas de los menores no están cubiertas, dando lugar a situaciones de maltrato físico y/o emocional, negligencia, abandono o abuso sexual.

Sus funciones se inscriben, por tanto, dentro de la red pública de protección de menores en base a la Ley 6/1995 de 28 de marzo de Garantías de los Derechos de la Infancia y la Adolescencia de la Comunidad de Madrid.

Entre las funciones de los Centros de Atención a la Infancia se encuentran la valoración de la situación y problemática psicológica y social del menor y su familia. De igual forma la orientación y tratamiento especializado, dirigido a prevenir y reducir los factores de riesgo, situaciones carenciales y/o conflictivas, fomentando la convivencia familiar y social. Si no es posible la aminoración del nivel de riesgo en el menor, promoción de la adopción de una medida de protección ante la Comisión de Tutela del Menor, continuando el seguimiento o intervención con objeto de trabajar, si es viable, la reincorporación del menor al medio familiar una vez sean diferentes las circunstancias familiares y no supongan riesgo para el menor.

En la práctica de los Centros de Atención a la Infancia se encuentran casos en los que menores de diferentes edades están insertos en un ambiente familiar con factores de riesgo, algunos de los cuales son el maltrato físico y psicológico por parte de otros integrantes del medio familiar, usualmente figuras parentales. Junto al funcionamiento del sistema de protección de menores y de las intervenciones destinadas a la modificación de las dinámicas y conductas de maltrato, tiene lugar la respuesta del sistema judicial penal. Esta respuesta, irrenunciable para el adecuado funcionamiento del orden social en los supuestos de comisión de ilícitos relacionados con maltrato a menores en el ámbito familiar, puede dar lugar a la aplicación de las medidas cautelares en fase de instrucción, y penas una vez practicado el correspondiente juicio oral con todas las garantías procesales del ordenamiento jurídico. Dichas conse- cuencias penales vienen recogidas en los artículos 153 y 173.2 del Código Penal ${ }^{1}$. Entre las mismas se encuentran la privación de libertad para el acusado, de conformidad con el tipo penal recogido en el Código Penal para este tipo de delitos. Asimismo, cuando el Juez o Tribunal lo estime adecuado al interés del menor o incapaz, la pena de inhabilitación para el ejercicio de la patria potestad, tutela, curatela, guarda o acogimiento durante un periodo de hasta cinco años. Lo anterior puede venir complementado por la adopción de penas de alejamiento del menor de la persona autora del maltrato en el ámbito familiar.

\footnotetext{
${ }^{1}$ Artículo 153 Código Penal.
}

El que por cualquier medio o procedimiento causare a otro menoscabo psíquico o una lesión no definidos como delito en este Código, o golpeare o maltratare de obra a otro sin causarle lesión, cuando la ofendida sea o haya sido esposa, o mujer que esté o haya estado ligada a él por una análoga relación de afectividad aun sin convivencia, o persona especialmente vu lnerable que conviva con el autor, será castigado con la pena de prisión de seis meses a un año o de trabajos en beneficios de la comunidad de treinta y uno a ochenta días y, en todo caso, privación del derecho a la tenencia y porte de armas de un año y un día a tres años, así como, cuando el Juez o Tribunal lo estime adecuado al interés del menor o incapaz, inhabilitación para el ejercicio de la patria potestad, tutela, curatela, guarda o acogimiento hasta cinco años.

Si la víctima del delito previsto en el apartado anterior fuere alguna de las personas a que se refiere el artículo 173.2, exceptuadas las personas contempladas en el apartado anterior de este artículo, el autor será castigado con la pena de prisión de tres meses a un año o de trabajos en beneficio de la comunidad de treinta y uno a ochenta días y, en todo caso, privación del derecho a la tenencia y porte de armas de un año y un día a tres años, así como, cuando el Juez o Tribunal lo estime adecuado al interés del menor o incapaz, inhabilitación para el ejercicio de la patria potestad, tutela, curatela, guarda o acogimiento de seis meses a tres años.

\section{Artículo 173.2 Código Penal.}

El que habitualmente ejerza violencia física o psíquica sobre quien sea o haya sido su cónyuge o sobre persona que esté o haya estado ligada a él por una análoga relación de afectividad aun sin convivencia, o sobre los descendientes, ascendientes o hermanos por naturaleza, adopción o afinidad, propios o del cónyuge o conviviente, o sobre los menores o incapaces que con él convivan o que se hallen sujetos a la potestad, tutela, curatela, acogimiento o guarda de hecho del cónyuge o conviviente, o sobre persona amparada en cualquier otra relación por la que se encuentre integrada en el núcleo de su convivencia familiar, así como sobre las personas que por su especial vulnerabilidad se encuentran sometidas a custodia o guarda en centros públicos o privados, será castigado con la pena de prisión de seis meses a tres años, privación del derecho a la tenencia y porte de armas de dos a cinco años y, en su caso, cuando el juez o tribunal lo estime adecuado al interés del menor o incapaz, inhabilitación especial para el ejercicio de la patria potestad, tutela, curatela, guarda o acogimiento por tiempo de uno a cinco años, sin perjuicio de las penas que pudieran corresponder a los delitos o faltas en que se hubieran concretado los actos de violencia física o psíquica.

Se impondrán las penas en su mitad superior cuando alguno o algunos de los actos de violencia se perpetren en presencia de menores, $o$ utilizando armas, o tengan lugar en el domicilio común o en el domicilio de la víctima, o se realicen quebrantando una pena de las contempladas en el artículo 48 de este Código o una medida cautelar o de seguridad o prohibición de la misma naturaleza. 
La respuesta penal al caso concreto del maltrato físico a menores debe ir más allá de la aplicación de las penas previstas y, en aplicación del principio tuitivo del menor, de habitual consideración en la práctica judicial, fiscal y administrativa, debe tener en cuenta, además de lo anterior, algunas situaciones que se vienen produciendo en la práctica y cuyas consecuencias en los ámbitos emocional y conductual de los menores merecerían una mayor atención y protagonismo con el fin de prevenir una victimización añadida en los mismos. La realidad es que en muchas de las relaciones materno filiales o paterno filiales en que han tenido lugar hechos presuntamente constitutivos de maltrato familiar suele haber, además, una relación vincular de una intensidad suficiente para que la ruptura de dicho vínculo de forma abrupta y duradera no deje indiferente al menor. Al contrario, como más abajo se expondrá en la breve selección de revisión de autores e investigaciones, las consecuencias que la nueva realidad impone al menor suponen una conmoción que, en el corto plazo afecta su esfera emocional, relacional, conductual y de salud, y que, en función de la evolución posterior, puede comprometer un adecuado desarrollo de su personalidad.

\section{Relación de algunos casos apreciados en la práctica de los centros de atención a la infancia}

\section{- Alfonso}

Alfonso es un menor de tres años de edad, en familia monoparental compuesta por la madre y él mismo. En consulta de pediatría hospitalaria se detectaron hematomas que, por su localización y configuración resultaban incompatibles con la producción accidental siendo sugestivos de maltrato físico. La puesta en funcionamiento del protocolo de detección de casos de maltrato infantil hizo que la situación se pusiera en conocimiento de la autoridad administrativa competente en materia de protección de menores, desde donde se acordó la adopción de la medida de tutela por el riesgo para la integridad física y emocional del menor y el incumplimiento de los deberes de protección inherentes a la patria potestad. A su vez, se dio traslado del pertinente parte al Juzgado de Guardia. Desde el Juzgado de Instrucción se acordó como medida cautelar orden de alejamiento de la madre respecto de su hijo hasta la celebración del juicio oral.

Junto a la medida de protección de tutela se acordó que la guarda del menor se llevara a cabo en la persona del Director de la Residencia de Menores, constituyéndose un acogimiento residencial. En los supuestos en que es adoptada una medida como la mencionada, el interés del menor hace que se contemplen las necesidades de relación del mismo con la figura de apego así como las circunstancias del caso, entre ellas el pronóstico de recuperabilidad de las competencias parentales y de reversibilidad de la medida. Del análisis de dichas variables puede deducirse la conveniencia para el menor de visitas de las figuras parentales de manera supervisada en la Residencia en que se encuentra guardado.

En el periodo posterior a la separación de Alfonso de la figura de su madre se detectaron en el menor una serie de síntomas que afectaban a diferentes áreas: Emocional: alternancia de episodios de irritabilidad con otros de humor disfórico; conductual: falta de energía e interés, actitud pasiva, falta de dinamismo e incremento de la intolerancia a las frustraciones; relacionales: avidez afectiva; y de salud física con propensión a caídas y accidentes y alteraciones del sueño.

Los síntomas mencionados, considerados tanto de manera individual como en su conjunto, conllevaban un importante efecto desestabilizador en la fase evolutiva en que se encontraba el menor pudiendo constituir, además, un factor de riesgo considerable de deslizamiento hacia estructuras de personalidad depresivas o actuadoras. En el caso de Alfonso la existencia de la orden de alejamiento determinó la imposibilidad de poder poner en práctica un programa de visitas supervisadas entre el menor y su madre con objeto de intentar aminorar la aparición o intensificación de dichos síntomas. Las consultas e informes emitidos al órgano judicial informando de la necesidad de permitir los contactos filio parentales no llevaron a una resolución judicial en el sentido solicitado. Celebrado el juicio oral, la madre resultó condenada por un delito de maltrato familiar imponiéndose la pena de privación de patria potestad y alejamiento del menor durante un periodo de tres años. Desde los técnicos de protección de meno- 
res se estableció contacto con el padre y familia paterna, los cuales se hallaban en su país de origen, realizándose los trámites, vía colaboración internacional, para la valoración de los mismos, con objeto de que se analizase la conveniencia de que Alfonso pasase a convivir con ellos, al tener la patria potestad y no obstante no haber tenido relación con el mismo.

\section{- Celia}

Celia es una menor de nueve años que fue tutelada por resolución de urgencia de Comisión de Tutela del Menor. La detección de la situación de posible maltrato se realizó en el colegio donde observaron marcas en la menor. Desde el centro se solicitó la intervención del SAMUR. Desde dicho dispositivo se trasladó a Celia a Centro Hospitalario. En dicho Centro se realizó exploración de la menor a raíz de la cual se efectuó la notificación de riesgo y maltrato infantil y el parte al Juzgado de Guardia. Se verificó asimismo el traslado de la menor al Centro de Primera Acogida así como la resolución de tutela de urgencia. Se informaba, asimismo, de la existencia de otras dos hermanas de Celia en el domicilio familiar: María y Ana.

El grupo familiar fue derivado al CAI al haberse establecido una medida de protección de tutela y ser éste el dispositivo desde el que se efectúa el seguimiento de la misma en coordinación con el centro residencial al que accedería la menor tras la confirmación de la resolución. A su vez se solicitaba al CAI que informara respecto a la valoración e intervención efectuada con el grupo familiar para considerar el mantenimiento, cese o cambio de medida.

Por parte del Ministerio Fiscal, en aplicación del ordenamiento jurídico se solicitó en su escrito de acusación pena privativa de libertad para el padre de Ana y marido de la madre de Celia. A su vez se solicitaba alejamiento de la menor durante un periodo de tres años.

La menor, una vez fue destinada a la residencia donde se efectuaría la guarda de la misma, tras su paso por el centro de primera acogida y transcurridas las primeras semanas, comenzó a manifestar una serie de síntomas: actitud pasiva, retraimiento social, sentimientos de desvalorización y baja autoestima, falta de dinamismo, reacciones de tristeza y llanto después de las visitas de sus hermanas y madre en la residencia que daban lugar a periodos de aflicción de varios días. De igual forma tenían lugar alteraciones en los patrones normales de sueño y alimentación.

En la valoración realizada desde el Centro de Atención a la Infancia pudo concluirse la existencia de un vínculo afectivo sólido entre Celia, su madre y pareja de ésta y sus hermanas. Dicho vínculo se ponía de manifiesto en las reacciones emocionales de satisfacción y alegría experimentadas por la menor cuando estaba en contacto con los padres y en las reacciones de tristeza y llanto expresadas cuando tenía lugar la separación entre ésta y su familia. A su vez dicho vínculo se había manifestado en el deseo verbalizado por la menor de volver a estar con su familia en repetidas ocasiones.

Las necesidades emocionales detectadas en la menor y la aptitud de los progenitores para aceptar y beneficiarse de una intervención psicosocial dirigida a la mejora de sus competencias parentales determinaron que en la Comisión de Apoyo Familiar del distrito se acordara el llevar a la práctica un programa gradual de contactos y visitas externo a la residencia, con seguimiento desde el Centro de Atención a la Infancia. Ello fue posible al no existir, en el presente caso, medida cautelar de alejamiento. En primer lugar se establecieron salidas de la menor con la familia sin pernocta. La repercusión positiva en la menor de dichas salidas supuso una progresión en el programa consistente en salidas de fin de semana con pernocta de que pudieran llevarse a cabo visitas de fin de semana con pernocta de Celia en el domicilio familiar, y con posterioridad vacaciones de navidad. La influencia de dichos periodos de convivencia familiar en la menor resultó positiva a nivel emocional y comportamental, reduciéndose en forma considerable la sintomatología presentada por la menor.

La evolución descrita y las circunstancias familiares concurrentes en el momento actual fueron examinadas en la Comisión de Apoyo Familiar del distrito donde, se acordó el cese de la medida de protección sobre Celia y la reincorporación de la misma al grupo familiar con seguimiento de la nueva situa- 
ción familiar desde el Centro de Atención a la Infancia. El fundamento de tal acuerdo se basaba en la convicción de que la separación de la menor de sus vínculos familiares como consecuencia del mantenimiento de la medida de protección suponía una circunstancia con consecuencias desestabilizadoras a nivel emocional para la misma que no podía ser desconocida, máxime si se tenía en cuenta la evolución positiva de los periodos de convivencia familiar y el hecho de no existir aún un pronunciamiento judicial, cautelar o definitivo, sobre los hechos objeto de denuncia.

La celebración del correspondiente juicio, meses después, dio lugar a que el Juzgado de lo Penal acordara la libre absolución de la pareja de la madre y padrastro de Celia al no existir prueba de cargo suficiente para desvirtuar el derecho de presunción de inocencia del acusado.

\section{- Marta}

Marta es una menor de 11 años, la cual fue tutelada mediante resolución de urgencia por presuntos malos tratos por parte de su progenitora. (El caso aún está pendiente de juicio y resolución judicial). La misma se personó en la comisaría de policía acompañada de su padre, denunciando bofetadas y golpes por parte de la madre en una discusión.. La menor ingresó el Centro de Primera Acogida a través del GRUME. El Juzgado de Instrucción que conoce de los hechos en virtud de auto judicial decretó orden de alejamiento y prohibición de comunicación de la madre respecto de la hija hasta que termine el procedimiento judicial.

En la Comisión de Apoyo Familiar del distrito se acordó derivación del grupo familiar al CAI al haberse establecido una medida de protección de tutela. De igual forma, desde el Juzgado se acordó el seguimiento de la menor desde los servicios sociales. En el seguimiento realizado se fue perfilando una realidad en la que se mostraba que el padre acudía a las visitas semanales programadas en el centro donde se encontraba la menor tutelada. Las mismas se caracterizaban por la constancia y fiabilidad de la presencia parental y la colaboración con las premisas trasladadas desde el centro. Se observaba, además, la existencia de un vínculo paternofilial, afecti- vo y sólido que aconsejaba la continuación de dichos contactos y el retorno al domicilio familiar. Paralelamente, se estaba llevando a cabo un trabajo con los padres de fortalecimiento de las competencias parentales, mejora de la dinámica de comunicación y criterios educativos en la adopción de decisiones consensuadas sobre las cuestiones relativas a la hija común. Los progenitores estaban colaborando en este proceso de intervención mostrando una positiva disposición para realizar los cambios pertinentes que permitieran modificar las circunstancias personales y relacionales que supusieran una dinámica familiar de protección hacia su hija.

Durante dicho proceso se pudo observar que la separación de la menor de sus vínculos familiares suponía una circunstancia con consecuencias desestabilizadoras a nivel emocional y relacional para Marta. La separación de la menor de su familia suponía periodos de aflicción repetidos para la misma tras los encuentros con el padre. La menor también expresaba sentimientos de tristeza y actitudes de abatimiento relacionándolos la misma con el hecho de no poder mantener contacto o comunicación con su madre. A su vez, volvían a producirse, como en el caso anterior, falta de energía e interés, actitud pasiva y sentimientos de desvalorización. Por otro lado tenía lugar, también, una disminución de la capacidad de concentración y del rendimiento escolar.

La realidad sintomática descrita no podía ser desconocida, así como el hecho de no existir orden de alejamiento judicial respecto del padre y la valoración de los recursos de protección de estar beneficiándose de la intervención psicosocial puesta en marcha. Junto a ello debía considerarse el hecho de no existir aún un pronunciamiento judicial definitivo sobre los hechos objeto de denuncia y poder transcurrir aún un periodo de tiempo prolongado hasta el mismo. En este contexto Comisión de Tutela del Menor decretó el cese de la medida de Tutela pasando la menor al domicilio familiar donde se hallaba el padre, y trasladándose la madre al domicilio de un familiar. Se ha solicitado, por otro lado, al Juzgado como un primer paso, la adopción de contactos supervisados, entre madre e hija, con el fin de posibilitar, por un lado, la prevención de efectos emocionales y relacionales negativos en la menor como consecuencia de una separación dura- 
dera y continua de la figura materna; y por otro lado permitir el trabajo de algunos aspectos de la relación materno filial en sesiones familiares con ambas.

\section{Investigaciones y estudios más significativos sobre deprivación materna y sus efectos en los menores}

El superior interés del menor hace que deban ser tenidas en cuenta los efectos que a nivel psicológico tienen en los menores a corto y largo plazo la separación de la figura del cuidador de referencia durante un largo periodo de tiempo. Esta realidad, que se ha venido poniendo de manifiesto por numerosos autores desde hace décadas y en ámbitos diferentes, parece no haber encontrado, aún, en el ámbito de la justicia la acogida de la que es acreedora por la trascendencia de sus consecuencias. Resulta útil, en este sentido, recordar brevemente a algunos de los autores más significativos que se han ocupado de los efectos de dicha privación en el menor:

Los estudios realizados sobre ruptura de vínculos entre menores de corta edad y sus figuras de apego y la aparición de trastornos mentales tienen una larga trayectoria. Entre los autores significativos para la cuestión objeto de reflexión puede citarse a Spitz (1965/1981). Dicho autor estudió las perturbaciones provocadas en los niños durante los primeros dieciocho meses de vida por un trastorno en las relaciones madre-hijo. Entre la población objeto de estudio destacaban niños criados en orfelinatos, o en hospitales, con privación completa de la presencia materna. El estudio y análisis detallado de los procesos por los que transitaban los menores y sus consecuencias a nivel físico y psíquico le permitió concluir la existencia de dos tipos de síndrome: Hospitalismo, en los casos de niños criados en ausencia completa de la madre, con privación afectiva total y donde los cuidados le eran proporcionados de forma anónima. Los trastornos ocasionados en dichos supuestos eran retardo del desarrollo corporal, de la habilidad manual, de la adaptación al medio ambiente, del desarrollo del lenguaje, de la disminución de la resistencia a las enfermedades y, en los casos más graves, marasmo y muerte. El otro síndrome sería la depresión anaclítica, la cual sería subsiguiente a una priva- ción afectiva parcial en un niño que, hasta entonces, habría disfrutado de una relación normal con su madre. Sus efectos serían pérdida de la expresión mímica, mutismo, anorexia, insomnio, pérdida de peso y retardo psicomotor. En este supuesto, dicha depresión podría revertir al volver a encontrar a la madre y retomar la relación con la misma.

Bolwy (1979/2006), por su parte, hace referencia a como, de manera reiterada, dos síndromes psiquiátricos y dos clases de síntomas asociados van precedidos por una elevada incidencia de rupturas de vínculos afectivos durante la infancia. Los síndromes son personalidad psicopática y depresión. Los síntomas asociados serían delincuencia persistente y suicidio.

En lo que se refiere a la personalidad psicopática, el autor británico refiere la investigación clásica de Earle y Earle (1961), en la cual sobre una muestra relativa a pacientes psiquiátricos ambulatorios, sesenta y seis de ellos estaban diagnosticados de psicopatía, y mil trescientos cincuenta y siete, con otro trastorno psiquiátrico. El criterio aplicado fue la ausencia de la madre durante seis o más meses antes de los seis años. Los autores hallaron una incidencia del mencionado criterio en un $41 \%$ para los psicópatas y de un $5 \%$ para el resto de trastornos psiquiátricos.

En el estudio de Craft, Stephenson y Granger (1964) se adoptó como criterio una ausencia de la madre o del padre, o de ambas figuras, antes de que el niño cumpliese los diez años. De 76 varones ingresados en un hospital, con problemática de psicopatía y agresividad, no menos de un $65 \%$ habían tenido tal experiencia en sus vidas.

En lo relativo a la depresión, Bolwy refiere los estudios de Greer, Gunn y Koller (1966) que dan cuenta de una incidencia muy elevada de pérdida de seres queridos durante la infancia entre los sujetos que intentaron suicidarse. Tales investigaciones encuentran, como hecho destacable el que tales pérdidas ocurrieron antes de cumplir el sujeto cinco años con tres veces más frecuencia en el grupo de tentativas de suicidio que en cualquiera de los grupos comparativos.

Los estudios de Winnicott, (1954/1991) sobre la relación entre deprivación y delincuencia establecieron la conclusión de que cuando existe una tendencia antisocial en un individuo ha habido una verdadera desposesión, es decir la pérdida de algo bueno 
que ha sido positivo en la experiencia del niño hasta ese momento y que luego ha sido retirado, siendo dicha experiencia positiva la relación continua con la madre. La retirada se habría extendido durante un periodo de tiempo superior al que el menor es capaz de mantener vivo el recuerdo de tal experiencia. Por tanto, en la base de la tendencia antisocial habría una experiencia buena, percibiendo el pequeño que la misma se ha perdido. El que los destinos del menor se dirijan hacia la tendencia antisocial o hacia una enfermedad psicótica dependerá del grado de madurez del incipiente yo. Si éste es suficiente se encaminaría hacia la primera, si es insuficiente, hacia la segunda.

Ainsworth, (1963) al estudiar los efectos en el niño de la privación materna, postuló que el desarrollo del infante, después del retorno a las condiciones normales tras un periodo de separación, depende de la edad en el momento de la separación y de la duración de la misma, además de si ha habido un sustituto maternal durante la separación, si ha mantenido contacto con los padres, de la cualidad adaptativa y de las relaciones antes del episodio de separación. Añadió, además, que ciertas funciones afectivas o cognitivas pueden estar más dañadas que otras, siendo el caso de aquellas que afectan la función verbal, la función de abstracción y la aptitud para establecer lazos interpersonales profundos y duraderos. Los sectores más vulnerables, pues, para esta autora serían el desarrollo del lenguaje, la capacidad de generalización y las relaciones sociales.

Recientes investigaciones han encontrado que el estrés psicosocial en menores de corta edad, concretado en la separación temprana del niño de la madre, da lugar a una predicción elevada de síntomas de trastorno esquizotípico de la personalidad en la adolescencia, ocasionando, además, un impacto negativo tanto en el vínculo parental como en los estilos de apego. (Anglin, Cohen, y Chen, 2008; Lahti. et al., 2009)

Resulta esclarecedor, de igual manera, analizar algunos instrumentos desarrollados en el ámbito de la salud mental con el fin de detectar factores de riesgo y señales de alarma que puedan informar, ya desde la primera infancia, de una probabilidad significativamente superior a la media de padecer un trastorno psicótico en la adolescencia y/o edad adulta si el sujeto no recibe una atención de salud mental preventiva y el entorno no recibe una contención y apoyo psicosocial adecuados.

En el Listado de Señales de Alarma y Signos Prodrómicos en la Esquizofrenia (SASPE), entre los antecedentes y factores de riesgo precoces en la infancia para el desarrollo de la esquizofrenia posterior, dentro de los factores relacionados con la socialización se encuentra la institucionalización temprana.

En el Listado de Items de Salud Mental (LISMEN) puede observarse como, entre los factores de riesgo detectados en los antecedentes de una población de pacientes con psicosis, un indicador con un elevado porcentaje de presencia en las historias clínicas $\left(35^{\prime} 3 \%\right)$ es el relacionado con la institucionalización temprana de los sujetos (instituciones tutelares e instituciones de justicia) (Tizón et al., 2008).

La reciente investigación publicada por Nelson, Furtado, Fox, y Zeanah (2011) con una población de niños institucionalizados resulta muy ilustrativa por su actualidad, la variedad de elementos investigados y las conclusiones alcanzadas. Tras el análisis de resultados y en la comparativa entre niños institucionalizados y no institucionalizados en régimen de acogida se concluía:

- El cien por cien de los niños que no habían tenido una experiencia de institucionalización mostraba un apego completamente desarrollado, mientras que únicamente el tres por ciento de los niños pertenecientes a la muestra de menores institucionalizados tenía vínculos completamente desarrollados.

- La muestra de niños institucionalizados mostró niveles significativamente más altos en el desarrollo de trastorno de apego reactivo que los niños que no habían tenido dicha experiencia en la infancia.

- El rendimiento intelectual de los niños con una crianza en instituciones también se vio afectado de manera muy significativa, siendo muy inferior comparado con el rendimiento intelectual de los niños criados en el seno de su familia biológica. Concretamente las mediciones a los 30 meses de edad del Cociente Intelectual medio de los niños con institucionalización fue de 74 puntos. El Cociente Intelectual medio del 
grupo sin experiencia de institucionalización fue de 103 puntos.

- Una novedad puesta en práctica en esta investigación fue la medición de la función cerebral mediante registros de Electroencefalograma, sugiriendo los resultados un retraso en el desarrollo cerebral de los niños del grupo institucionalizado.

- Los niños sin experiencia de institucionalización mostraron la esperada especialización del hemisferio derecho en cuanto al reconocimiento de rostros. Sin embargo, los niños del grupo de institucionalizados no mostraron esta cualidad.

Señalar por último las consideraciones realizadas recientemente por Jorge L. Tizón (2011) relativas al funcionamiento de los niños criados en instituciones, los cuales en situaciones de estrés, angustia y desorganización, tienden a desorganizarse o a responder inadecuadamente en dichas circunstancias. Además de enfermar más y poseer una tendencia mayor al desarrollo de trastornos de personalidad, tal y como también han postulado en sus últimas investigaciones autores como Fonagy (2002), Feder (2009) y Knauer y Palacio (2010).

\section{Resoluciones judiciales que recogen fallos en el sentido descrito}

Es ilustrativo detenerse en algunas resoluciones judiciales con el fin de observar la respuesta que el orden penal debe ofrecer en aplicación del ordenamiento jurídico disponible y los mecanismos puestos en práctica por los órganos judiciales con objeto de intentar aminorar los efectos de una interrupción brusca y duradera de la relación vincular.

- Sentencia del Juzgado de lo Penal n³ de Jaén, de 26 de noviembre de 2008. Declara a la madre autora responsable de un delito de malos tratos contra su hijo de diez años, condenando a la pena de cuarenta y cinco días de prisión, con la accesoria de inhabilitación especial para el ejercicio del derecho de sufragio pasivo, privación de la tenencia y porte de armas durante seis meses y prohibición de aproximarse a menos de 500 metros con su hijo durante un año y cuarenta y cinco días. Dicha sentencia fue recurrida por el Ministerio Fiscal solicitando el incremento de las penas impuestas, resolviendo la sección segunda de la Audiencia Provincial de Jaen conforme a la solicitud del Ministerio Público y elevando la pena impuesta a la madre imponiéndole 67 días de prisión, así como un año y 67 días de alejamiento del menor. Debe añadirse que la Audiencia Provincial solicitó al Ministerio de Justicia el indulto de la pena de prohibición de aproximación, con la consiguiente suspensión de su ejecución, ya que consideraba que su aplicación podía conllevar consecuencias perjudiciales para los dos hijos menores de esta madre. El Consejo de Ministros concedió finalmente el indulto solicitado.

- Sentencia de 30 de noviembre de 2010 del Juzgado de lo Penal $n^{\circ} 7$ de Valencia condenando a la madre por un delito de malos tratos contra su hija de ocho años a la pena de cincuenta y seis días de trabajo en beneficio de la comunidad, privación de custodia y prohibición de aproximación a la menor durante dos años. Dicha resolución fue anulada por la Audiencia Provincial de Valencia, mediante sentencia de fecha 8 de abril de 2011, que absuelve del delito de malos tratos y condena por una falta de maltrato de obra a la pena de un mes de multa con una cuota diaria de seis euros.

- Sentencia de 23 de diciembre de 2009 del Juzgado de lo Penal $n^{\circ} 9$ de Madrid. Condenó a la madre por un delito de lesiones en el ámbito familiar respecto de su hijo de once años a la pena de cuarenta y cinco días de trabajo en beneficio de la comunidad así como a la pena accesoria de prohibición de aproximarse y comunicar con el hijo durante dos años y un día. La Sentencia de 20 de septiembre de 2010 de la Audiencia Provincial de Madrid, rebajó la pena a veintitrés días de trabajo en beneficio de la comunidad y la accesoria de prohibición de aproximarse y comunicar con su hijo a tres meses, alegando que "necesariamente ha de tener en el futuro una relación personal e intensa con su madre."

- Auto del Juzgado de Instrucción n ${ }^{\circ} 25$ de Madrid de 18 de abril de 2011 en el que se acuerda la 
medida cautelar consistente en prohibir a la madre cualquier aproximación a su hija de once años y a comunicarse con ella por cualquier medio durante el tiempo que dure la instrucción y hasta que termine el procedimiento por sentencia firme o sobreseimiento de la causa. Dicha resolución intenta conjugar la aplicación de la norma con el respeto a las necesidades emocionales de la menor al acordar, además, que se oficie a los servicios sociales para que hagan un seguimiento de la menor e informen periódicamente sobre la situación y evolución familiar con posibles propuestas de contacto entre la madre y la hija por si fuera necesario adoptar alguna modificación de la medida cautelar.

\section{Reflexiones y propuestas}

El estado de cosas descrito hace que se planteen diferentes reflexiones:

La puesta en relación de ambas dimensiones, jurídica y psicológica, lleva a pensar la Ley y la aplicación del sistema jurídico como fundamentales en la constitución de la subjetividad de los individuos. El establecimiento de los límites por medio del advenimiento de aquéllas, su función de encuadrar lo prohibido y lo permitido y, por tanto, de instaurar una falta poniendo coto a los excesos hace que se pongan límites a un funcionamiento basado únicamente en el principio del placer, estructurando, de esta manera, la subjetividad y posibilitando el funcionamiento de los sujetos en el orden social y con un mayor predominio del principio de realidad.

La Ley supone, en los supuestos que nos ocupan, una función de corte, de tercero que permita la diferenciación de sujetos progenitor e hijo y evita el riesgo de confusión entre ambos a la vez que instala un orden por el que impide que el sujeto niño quede alienado en la posición imaginaria de objeto fálico de la figura parental y objeto inconsciente de goce de la misma a través del maltrato. La necesidad de la aplicación de la ley resulta, pues, imprescindible para la puesta en práctica de la limitación de ese goce y de transmisión de una realidad que reconozca la diferencia de ambas subjetividades y la preservación de la parte acreedora de protección. Sin embargo la realidad es compleja y, junto a esta dimensión, hay otra que viene definida por la existencia de un vínculo, con manifestaciones emocionales y relacionales, cuya interrupción duradera y sin contactos puede dar lugar a consecuencias perjudiciales y desestabilizadoras para el menor. El desconocimiento de esta realidad puede ocasionar un deslizamiento en la aplicación de la ley, al no ser consideradas las consecuencias de la separación en menores de las figuras parentales en estos casos, que daría lugar a indeseados efectos perversos en dicha aplicación.

Así las cosas, resulta procedente, dar lugar a un espacio de encuentro entre la efectiva realización de la justicia y las necesidades vinculares, emocionales y psicológicas de los menores de edad que dé respuesta a la exigencia de seguridad jurídica en este campo. Dicha realidad ha de venir dada por la necesidad de contemplar un mecanismo corrector de los riesgos mencionados que puede materializarse a través de matizar las ordenes de alejamiento o privaciones de patria potestad, tutela, guarda o acogimiento con un sistema de contactos o visitas bien en los puntos de encuentro familiar, bien en las residencias de protección en las que pueden encontrarse los menores si se ha acordado una medida de tutela por la entidad administrativa competente. En tales casos dichos contactos deberán estar supervisados por profesionales que velen por que dichos encuentros supongan una repercusión positiva en el niño y realicen el seguimiento de los mismos a la luz del superior interés del menor.

Desde luego, la toma en consideración de tales riesgos ha de ser conciliada con el prioritario interés de la salvaguarda de la integridad física y psíquica del menor. Por ello la procedencia de tener en cuenta un régimen de visitas profesionalmente supervisadas entre menor y progenitor habrá de ir precedida, en cada caso, de un exhaustivo análisis de determinados factores que necesariamente habrán de ser examinados con objeto de valorar y decidir su pertinencia en el caso concreto:

- Ausencia de gravedad de las lesiones producidas o de los daños psíquicos ocasionados, pudiendo contemplarse este mecanismo para casos en que no exista un alto nivel de gravedad. 
- Falta de continuidad en el tiempo de las lesiones o daños realizados siendo más conveniente la valoración de dichos contactos en supuestos de producción ocasional de las mismas.

- Previsión de riesgo bajo de nueva ocurrencia de los hechos objeto de intervención.

- Capacidad del progenitor supuestamente causante de las lesiones para la aceptación de los hechos ocurridos y aptitud para tomar conciencia y asumir lo reprochable de su acción.

- Permeabilidad para beneficiarse de un tratamiento dirigido a la mejora de sus competencias parentales y para la puesta en práctica de la función normativa de manera proporcionada a la edad del menor y de forma respetuosa con su integridad emocional y física.

- En el supuesto de que ya haya tenido lugar la separación del menor de la figura de apego de forma cautelar, la calidad e intensidad de la sintomatología emocional y alteraciones comportamentales y relacionales del menor.

Lo anterior debe venir complementado con un esfuerzo de los diferentes actores para que la habitual consideración y puesta en práctica del interés superior del menor en sus respectivos ámbitos encuentre también aplicación en los casos referidos. Desde los profesionales de la psicología o la intervención social haciendo llegar a los órganos judiciales y ministerio público, en cada caso concreto y antes de la adopción de resoluciones cautelares o definitivas, las exactas consecuencias para los menores de las separaciones afectivas prolongadas de sus figuras de apego sin una matización que pase por contactos supervisados por profesionales que mitigue los efectos de la pérdida en alguien que, en ocasiones, aún no dispone de herramientas psíquicas para su comprensión y elaboración.

Desde las autoridades con competencias en la materia, la necesidad de una sensibilidad que contemple no sólo la estricta aplicación de la letra de la ley sino también la evitación de la extensión no buscada de la victimización a menores, contemplando un régimen de contactos del menor con la madre o el padre supervisados por profesionales. Tal extremo encontraría aplicación en diferentes niveles: A nivel legislativo, contemplando la procedencia de una incorpora- ción al Código Penal de un párrafo considerando la necesidad de matizar la aplicación de la pena de inhabilitación para la patria potestad o medida cautelar de orden de alejamiento, con el hecho de prevenir las consecuencias emocionales y conductuales descritas en los menores por la interrupción absoluta y duradera del contacto con la figura vincular.

A nivel del Ministerio Público con la consideración de dichos principios a la hora de realizar las solicitudes de medidas cautelares en las comparecencias judiciales y de penas en los escritos de acusación, solicitando al órgano judicial que recabe, con carácter previo y por medio del equipo técnico psicosocial, la exploración de los menores y el análisis de las relaciones vinculares y los previsibles efectos de su interrupción abrupta y prolongada.

A nivel de los Órganos Judiciales con la integración de la realidad descrita y sus consecuencias en la función de valoración de los hechos y aplicación de la ley en las resoluciones judiciales de manera que se contemple no sólo la estricta aplicación de la letra de la ley sino también la evitación de la extensión no buscada de la victimización a los menores. Del análisis de las sentencias reseñadas se desprende la existencia de una actitud en los órganos judiciales tendente a encauzar tales desviaciones consecuencia de la estricta aplicación de la letra de la ley, ya sea por la solicitud de indultos, ya sea por la revisión de las sentencias en segunda instancia aplicando la pena mínima. En algunos casos se oficia a los servicios sociales para que, previo seguimiento de la menor, se informe sobre la pertinencia de contactos con la madre.

El principio de favor filii, informador de las ramas del Derecho en que haya que priorizar el interés del menor, la necesidad de preservar a los menores de perturbaciones como las analizadas, y la conveniencia de incrementar la seguridad jurídica en estos casos lleva a la oportunidad de incorporar en la práctica de cada uno de los profesionales implicados reflexiones sobre los efectos en los niños de la ruptura brutal y duradera de los vínculos familiares. Ello ayudará, quizá, a avanzar en la línea de dar una respuesta integral y comprensiva de la complejidad de dimensiones existente en la protección de menores en cada caso concreto. 


\section{Referencias}

Ainsworth, M. (1963). Privación de los cuidados maternos. Revisión de sus consecuencias. Ginebra: OMS, Cuadernos de Salud Pública, 14, 102104.

Anglin, D., Cohen, P. y Chen H. (2008). Duration of early maternal separation and prediction of schizotypal symptoms from early adolescence to midlife. Schizophrenia Research, 103, 143-150.

B.O.E. ${ }^{\circ} 0183$ de 2 de agosto de 1995. Ley 6/1995 de 28 de marzo de Garantías de los Derechos de la Infancia y la Adolescencia de la Comunidad de Madrid.

Bolwy, J. (2006). Vinculos afectivos: Formación, desarrollo y pérdida. Madrid: Ediciones Morata. (Trabajo original publicado en 1979).

Craft, M., Stephenson, G. y Granger, C. (1964). The Relationship Between Severity of Personality Disorder and Certain Adverse Childhood Influences. British Journal of Psychiatry, 110, 392-396.

Earle, A. y Earle, B. (1961). Early Maternal Deprivation and Later Psyquiatric Illness. American Journal of Orthopsyquatry, 3, 181-186.

Feder, A., Nestler E. y Charney D. (2009). Psychobiology and molecular genetics of resilience. Nature reviews, 10, 446-457.

Fonagy, P., Gergely, G., Jurist, E. y Target M. (2002). Affect Regulation, Mentalization and the Deve-lopment of the Self. Nueva York: Other Press.
Gimbernat, E. y Mestre E. (2011). Ley Orgánica 10/1995 de 23 de noviembre, del Código Penal. Madrid: Tecnos.

Greer, S., Gunn, J. y Koller, K. (1966). Aetiological Factors in Attempted Suicide. British Medical Journal, 2, 1355- 1357.

Jiménez de Asúa, L. (1947). Psicoanálisis criminal. Buenos Aires: Editorial Losada.

Knauer D. y Palacio, F. (2010). La destinée des bébés, Pert-elle changer? Études cliniques longitudinales du bébé à l'adult. Paris: Ed. PUF.

Lahti et al. (2009). Early-life origins of schizotypal traits in adulthood. British Journal of Psychiatry, 195, 132-137.

Nelson, C., Furtado, E.; Fox, N. y Zeanah, C. (2011). Los años sensibles. Mente y Cerebro, 46, 9-17.

Spitz, R. (1981). El primer año de vida del niño. Madrid: Editorial Aguilar. (Trabajo original publicado en 1965).

Tizon, J., Artigué, J., Parra, B. Sorribes, M. Ferrando, J., Pérez, C., ... Marzzari, B. (2008). Factores de riesgo para padecer trastornos psicóticos: ¿Es posible realizar una detección preventiva? Clínica y Salud, 19, 27-58.

Tizón, J. (2011). Crianza de los hijos y actividad laboral: ¿Cómo aproximarnos hacia la necesaria conciliación? (y II). Revista de Psicopatología y Salud Mental del Niño y del Adolescente, 18, 15-32.

Winnicott. D. W. (1991). Deprivación y delincuencia. Barcelona: Editorial Paidos. (Trabajo original publicado en 1954).

Manuscrito recibido: 08/02/2012 Revisión recibida: 25/04/2012 Aceptado: 27/04/2012 